\title{
Overcoming Negative Synergy in the Classroom: Avoiding a Teaching Nemesis
}

\section{Mayes D. Mathews • Shannon Jackson}

Published online: 18 February 2009

(C) International Atlantic Economic Society 2009

In the classroom, one pedagogical technique used to improve student classroom participation and to introduce various levels of collaborative efforts among the students is the group project. Presented here is a paradigm shift in this useful classroom instruction technique that assumes that having the group members work together will generate a situation where a condition of synergy of effort will exist. Synergy is seen to be the outcome of a system output where the resultant whole of the collaborative effort is greater than the sum of the individual parts. The concept of negative synergy is introduced as a special case of synergy where the whole is less than the sum of its parts.

A new model of teaching under conditions of potential negative synergy is introduced as well as several suggested ways to reverse situations where classroom teaching efforts may be sent into a destructive, degenerative loop. The only being that can bring and influence change upon groups that are so oriented is seen to be the facilitator or teacher of the errant group. Negative synergy presents an interesting new way to increase comprehension of the understanding of how group members interact with each other. This paper will examine negative synergy in classroom groups and will suggest some countermeasures that might be used by the instructor to improve the classroom chances for future success under conditions exhibiting such features of potential negative synergy.

A paper for the: International Atlantic Economic Society at Savannah, Georgia, Session A20 Teaching Economics On 7-19 October, 2007.

M. D. Mathews $(\bowtie)$

Saint Leo University, Postal Box 99, Toano, VA 23168, USA

e-mail: mayes.mathews@saintleo.edu

M. D. Mathews

International Atlantic Economic Society at Savannah, Savannah, GA, USA

S. Jackson

Saint Leo University, Postal Box 4326, Fort Eustis, VA 23604, USA

e-mail: shannon.jackson@saintleo.edu 